\title{
Vivências e Representações sobre o Crack: Um Estudo com Mulheres Usuárias
}

\author{
Katruccy Tenório Medeiros - Universidade Federal da Paraíba, João Pessoa, Brasil \\ Silvana Carneiro Maciel - Universidade Federal da Paraíba, João Pessoa, Brasil \\ Patrícia Fonseca de Sousa - Universidade Federal da Paraíba, João Pessoa, Brasil \\ Giselli Lucy Sonza Vieira - Universidade Federal da Paraíba, João Pessoa, Brasil
}

\begin{abstract}
Resumo
Este estudo objetivou conhecer e analisar as representações sociais acerca do crack elaboradas por dependentes químicas em tratamento, utilizando a Teoria das Representações Sociais. Participaram 45 usuárias de crack (idade média de 29,11 e DP = 7,99), internas em comunidades terapêuticas e clínicas de reabilitação, nos estados da PB e PE. Como instrumentos, foram utilizados um questionário e uma entrevista semiestruturada. Os dados foram analisados por meio do software Alceste. Os resultados indicaram que o crack é representado como um elemento devastador e desagregador, responsável por causar abandono ou afastamento das funções femininas. Verificou-se ainda que a figura da mulher usuária é vista como um problema de ordem moral, ocasionando uma representação depreciativa. Essas construções, ao mesmo tempo em que são individuais e sociais, exercem influência na forma como a sociedade encara a mulher dependente química, reforçando barreiras sociais que dificultam a procura de tratamento e a recuperação das usuárias.
\end{abstract}

Palavras-chave: crack, mulher usuária, dependência química, representação social

Experiences and Representations about Crack: An Approach to Female Drug-Users

\begin{abstract}
This research aimed at knowing and evaluating crack-related social representations as elaborated by under-treatment drugaddicts, using the Theory of Social Representations. 45 crack-users on an internship program in Therapy Communities and Rehabilitation Centers in the States of PB and PE participated in the referred study. As instruments for this approach, a questionnaire and a semi-structured interview were used. The data was analyzed by the Alceste software. Outcomes showed that crack is represented as a devastating and disaggregating element that leads to the abandonment and digression of female functions. It was also highlighted that the figure of the female user is accounted as a major moral-order problem, resulting in a depreciative representation. These constructions, as being individual and social at the same time, lead to a great influence over how society sees the female drug-addict, strengthening social barriers which make it difficult to achieve treatment, and the recovery of the user.

Keywords: crack, female user, drug addiction, social representations
\end{abstract}

Experiencias y Representaciones sobre el Crack: Un Estudio con Mujeres Usuarias

\section{Resumen}

Este estudio tuvo como objetivo conocer y analizar las representaciones sociales sobre el crack elaboradas por dependientes químicas en tratamiento, utilizando la Teoría de las Representaciones Sociales. Participaron 45 usuarias de crack (edad media de 29,11 y DT = 7,99), internas en Comunidades Terapéuticas y Clínicas de Rehabilitación, en los Estados de PB y PE. Como instrumentos, fueron utilizados un cuestionario y una entrevista casi estructurada. Los datos fueron analizados por medio del software Alceste. Los resultados indicaron que el crack es representado como un elemento devastador y disgregador, responsable por causar abandono o alejamiento de las funciones femeninas. Se verificó también que la figura de la mujer usuaria es vista como un problema de orden moral, ocasionando una representación despreciativa. Esas construcciones, al mismo tiempo que son individuales y sociales, ejercen influencia en la forma en que la sociedad encara a la mujer dependiente química, reforzando barreras sociales que dificultan la búsqueda de tratamiento y la recuperación de las mismas.

Palabras clave: crack, mujer usuaria, dependencia química, representación social

\section{Introdução}

Por muito tempo, tinha-se em mente que o uso abusivo de drogas, bem como a dependência química, eram fenômenos restritos ao universo masculino. Acreditava-se que os homens eram mais propícios ao abuso de drogas, principalmente devido a aspectos sociais e culturais e à associação do sexo masculino com a violência, virilidade e transgressão. Tais suposições apareciam vinculadas a produções discursivas que reforçavam as habilidades masculinas para práticas que garantiam maior acesso às drogas (Campos, Trindade, \& Coelho, 2008; Hochgraf \& Andrade, 2006).

Atualmente, entende-se que o consumo de substâncias, sejam elas ilícitas ou lícitas, ocorre em todos os grupos sociais, englobando mulheres, homens, 
adolescentes, idosos e, até mesmo, crianças. Dessa forma, não existe a ocorrência desse fenômeno em um único grupo social ou em uma faixa etária exclusiva. Não obstante, as interpretações que a sociedade atribui ao indivíduo usuário de drogas perpassam pelas construções socioculturais dos grupos aos quais pertencem os indivíduos. No caso das mulheres, essa "carga social" é permeada pelas construções de gênero na sociedade (Colling, 2004).

Estudos epidemiológicos (Carlini, Galduróz, Noto, \& Nappo, 2002) apontam para uma possível tendência à "igualdade de gênero" no consumo de drogas, o que, segundo Oliveira, Nascimento e Paiva (2007), é justificado por mudanças no estilo de vida das mulheres, ocorridas, sobretudo, no século passado. O fato de que as mulheres constituem um subgrupo vulnerável ao consumo de drogas, principalmente de pedras de crack, vem se tornando visível nas últimas décadas. Ao analisar dados da população mundial, segundo relatório do United Nations Office on Drugs and Crime - UNODC (2012), estima-se que entre 14 e 20 milhões de pessoas sejam usuárias de crack; sendo relatada a presença das mulheres cada vez mais frequente nas estatísticas em diversos países.

Em pesquisa de abrangência nacional realizada pela FIOCRUZ (Brasil, 2013), estima-se que, no país, há cerca de 370 mil usuários de crack, dos quais $21,3 \%$ são mulheres, com média de idade de 29,6 anos, solteiras (54\%) de cor não branca (78\%), sendo que uma ampla maioria possuía baixa escolaridade, até o Ensino Fundamental (80\%). Observou-se ainda que uma proporção expressiva de mulheres relatou engajamento em trabalho sexual ou troca de sexo por dinheiro $(55 \%)$, números estes, substancialmente mais elevados do que aquele referido pelos usuários do sexo masculino (14\%). Outros estudos realizados por Marangoni (2010), Medeiros (2014) e Nappo et al. (2004), também apontam para uma prevalência de mulheres adultas jovens, em idade economicamente ativa, baixa escolaridade, fora do mercado formal de trabalho e com vivências maternas em suas trajetórias. Em pesquisa realizada por Santos e Almeida (2013) com usuárias de um CAPS AD, mostrou uma associação entre o aumento do número de filhos e o baixo nível instrucional das mulheres, em que $82 \%$ das entrevistadas não completaram o ensino fundamental, e $47 \%$ tinham entre quatro ou mais filhos.

Em contexto internacional, um estudo realizado no Canadá ressalta usuárias vivendo em precárias condições, apresentando envolvimento com o trabalho sexual e menos apoiadas pela divulgação de serviços de saúde (Bungay, Johnson, Varcoe, \& Boyd, 2010). Sobre a baixa adesão das usuárias aos serviços de saúde especializados, essa questão também é evidenciada no contexto brasileiro, devido à generalização da abordagem de tratamento, que não levam em consideração as necessidades específicas femininas, como aponta Hochgraf e Andrade (2006).

Embora o consumo de drogas seja um fenômeno pouco explorado em estudos científicos, principalmente de abrangência nacional, até pouco tempo a mídia é que se encarregava de abordar o tema, na maioria das vezes, por meio de campanhas preconceituosas, de cunho sensacionalista, que estigmatizaram a imagem dos usuários, associando-os à violência e à marginalidade; no caso específico das mulheres, estas foram associadas à promiscuidade e/ou a casos de negligência familiar.

Apesar de ainda ser relatado nas estatísticas como menos frequente do que nos homens, o uso de drogas pelo público feminino, principalmente o uso de crack, vem sendo apontado como um fenômeno preocupante, que tem despertado novos desafios sociais para essa população e novas demandas para as políticas públicas de saúde. Soma-se a isso o fato de que a entrada das mulheres na dependência geralmente é acompanhada pela falta de condições financeiras para adquirir as drogas, o que pode levá-las a atividades ilícitas ou a praticar sexo em troca de drogas ou de dinheiro, submetendo-se ao risco de gravidez indesejada, de infecção pelo HIV/ AIDS ou outras doenças sexualmente transmissíveis (DST) (Nappo et al., 2004; Yamaguchi, Cardoso, Torres, \& Andrade, 2008).

Diversos autores têm relatado a ocorrência de danos individuais e sociais à saúde materno-infantil causados pela droga, especialmente no que tange ao uso de crack (Marangoni, 2010; Marangoni \& Oliveira, 2012; Yamaguchi et al., 2008). Apesar disso, pouco conhecimento científico se tem produzido, a partir de uma perspectiva psicossocial, remetendo às vivências e aos significados que o crack tem na vida dessas mulheres, como também às barreiras no enfrentamento dessa problemática.

Em vista dessa lacuna, a presente pesquisa optou por investigar tal problemática à luz de uma perspectiva psicossocial, embasada na Teoria das Representações Sociais (TRS). Segundo a definição clássica apresentada por Jodelet (2001), as representações sociais podem ser entendidas como modalidades de conhecimento prático, orientadas para a comunicação e para a compreensão do contexto social, material e ideativo em 
que vivemos. Por serem expressões de conhecimento, manifestam-se como elementos cognitivos, tais como imagens, conceitos, categorias e teorias, mas não se reduzem a esses componentes cognitivos, sendo, de preferência, socialmente elaboradas e compartilhadas. Em função disso, as representações contribuem para a construção de uma realidade comum, que possibilita a comunicação entre os grupos, facilitando, assim, a compreensão dos fenômenos. Avaliada como de bastante utilidade para a Psicologia Social, a Teoria das Representações Sociais permite a compreensão da subjetividade envolvida nas práticas cotidianas (Coutinho, Araújo, \& Gontiés, 2004).

Com base nisso, o objetivo deste estudo é conhecer e analisar as representações sociais do crack, elaboradas por mulheres usuárias em tratamento, que podem ajudar a entender os significados atribuídos a esse objeto social, guiando suas vivências e interpretações acerca do fenômeno das drogas. A intenção principal é contribuir para o conhecimento de elementos que possam auxiliar na prevenção do abuso e da dependência de substâncias psicoativas no grupo de mulheres.

\section{Método}

Consiste em uma pesquisa de campo, descritiva e de cunho qualitativo, com uso de entrevista semiestruturada, uma vez que, como esclarece Minayo (2012), aprofunda-se no universo dos significados, motivos, aspirações, crenças, valores e atitudes, preocupando-se com um nível de realidade que não pode ser quantificado.

\section{Participantes}

Por meio de uma amostragem não probabilística e de conveniência, foram selecionadas 45 mulheres usuárias de crack, que se encontravam em tratamento em comunidades terapêuticas (34) e clínicas de reabilitação (11), exclusivas para tratamento de mulheres tóxico-dependentes, localizadas nos estados de Paraíba-PB e Pernambuco-PE. A idade variou entre 18 e 42 anos $(M=29,11 ; D P=7,99)$, solteiras $(62 \%)$, com renda de 1 a 3 salários mínimos (49\%), prevalecendo a escolaridade entre analfabetas/fundamental incompleto $(58 \%)$. Foram incluídas as participantes que estavam internas nos locais escolhidos para a coleta, com idade maior que 18 anos e que aceitaram participar do estudo. Excluíram-se as que apresentavam condições cognitivas que comprometessem a compreensão dos instrumentos.

\section{Instrumentos}

Os dados foram coletados por meio de: (a) questionário sociodemográfico, com questões relacionadas a: idade, escolaridade, renda, estado civil, entre outras necessárias para caracterização da amostra; e (b) entrevista semiestruturada acerca do crack com questões, como: "O que significa o crack para você?"; "O que você entende por dependência química?"; "Fale sobre o início do uso?"; "Fale sobre o que você pensa que o crack trouxe para sua vida e pode trazer para a vida da mulher usuária?”. Por ser uma entrevista semiestruturada, as questões apresentadas podiam ser realizadas ou não a depender do que a entrevistada trazia no seu discurso, podendo ser aprofundadas questões trazidas espontaneamente ou mesmo inverter a ordem das perguntas. De forma a tornar a entrevista um momento de escuta das vivências, preservando a espontaneidade do discurso e suas subjetividades.

\section{Procedimento}

A presente pesquisa obteve a aprovação do Comitê de Ética em Pesquisa, localizado no Centro de Ciências da Saúde da Universidade Federal da Paraíba (CEP/ CCS-UFPB), sob o protocolo de $\mathrm{n}^{\circ}$ 0349/12, respeitando-se todos os cuidados éticos com pesquisa envolvendo seres humanos.

A fase de coleta de dados ocorreu nos próprios locais institucionais, em salas reservadas que possibilitaram a gravação das entrevistas. Estabelecido o rapport e esclarecido o propósito da pesquisa, solicitou-se às participantes a assinatura do Termo de Consentimento Livre e Esclarecido.

As entrevistas foram gravadas, transcritas e submetidas a uma análise lexical, realizada a partir do software ALCESTE (Análise Lexical por Contexto de um Conjunto de Segmentos de Texto). Consiste em uma análise de dados textuais, em que a operacionalização ocorre no processamento automático de materiais de análise (no caso deste estudo, o corpus foi constituído pelas 45 entrevistas realizadas). O software obtém uma primeira classificação estatística de enunciados simples, em função da distribuição de palavras dentro do corpus, a fim de apreender as palavras que lhes são mais características. A partir disso, o corpus é dividido em classes e eixos pelo programa, de forma que cada eixo contém as classes as quais representam um agrupamento específico (denominado à posteriori pelo pesquisador), levando em consideração os dados do software e o seu conteúdo lexical específico (Camargo, 2005; Reinert, 1993). 


\section{Resultados e Discussão}

No que se refere à caracterização da amostra estudada, as participantes encontravam-se na faixa etária de 26 a 33 anos (45\%), solteiras (62\%), analfabetas ou tinham o curso fundamental completo/incompleto $(58 \%)$, encontravam-se inseridas em trabalhos informais $(40 \%)$ ou diziam ser do lar (29\%). Quanto ao número de filhos, 51\% afirmou ter entre um e dois filhos, seguida das que diziam ter entre três e quatro filhos (31\%). A partir da presente análise, pode-se obter informações que permitem caracterizá-las como, em sua maioria, mulheres jovens, que se encontravam em idade reprodutiva, com nível de escolaridade abaixo do esperado para a idade e que estavam fora do mercado formal de trabalho, corroborando com os dados da literatura que associa o uso de crack com pobreza, situações de extrema vulnerabilidade e exclusão social.

No processamento de análise padrão do Alceste, o corpus foi constituído de 45 Unidades de Contexto Iniciais (UCI), totalizando 76.438 palavras. A classificação hierárquica descendente reteve $77 \%$ do total das Unidades de Contexto Elementares (UCE) do corpus, organizadas em dois eixos e quatro classes. A Figura 1 mostra o dendrograma formulado pelo Alceste, contendo a organização dos eixos e das classes, sendo expressas as palavras que obtiveram qui-quadrado de maior índice; apresentando a articulação dos seguintes eixos: eixo 1 - Experiências e vivências femininas do uso do crack e eixo 2 - O crack e seus fatores de recuperação, entendidos como complementares quanto à interpretação do fenômeno em análise, nesses grupos de pertença. Nesse entrelaçamento de eixos, pode-se observar a presença de elementos relacionados às perspectivas passadas e futuras, em relação ao uso do crack.

No eixo 1, encontram-se as classes 1 e 2 , as quais remetem às consequências do uso de crack e ao início do consumo, respectivamente. Os discursos emergidos nessas classes revelaram os motivos que levaram as usuárias à aproximação inicial do crack, e as consequências desse consumo na vida das mulheres. $\mathrm{O}$ eixo 2 abarcou as classes 3 e 4 , as quais envolvem elementos referentes tanto aos fatores que ajudam na recuperação da mulher dependente química, quanto aos discursos que denotam o desejo de tratamento. Nesse eixo, situam-se discussões em torno da reabilitação e do desejo de mudança por parte das usuárias.

A seguir, serão descritas as classes na ordem dada pelo programa conforme pode ser visto na Figura 1, sendo expressas as palavras com o qui-quadradro que obtiveram maior frequência e os dados sociodemográficos mais característicos das classes:

\section{Classe 1 - Consequências do Uso do Crack}

A classe 1, denominada Consequências do uso de crack, compreendeu 298 UCE, com 131 palavras analisadas e representou 25,0\% do corpus. Os relatos dessa primeira classe remetem às consequências orgânicas, sociais e econômicas da droga. As variáveis descritivas mais significativas foram a faixa etária de 26 a 33 anos, a situação conjugal de união estável e o fato de que diziam serem do lar.

No que se refere às consequências orgânicas, elas ocorreram, sobretudo, na degradação física do corpo e na aparência da dependente. Nessa categoria, ganharam destaque as palavras "quilos", "dormir" e "dedo", as quais expressaram a perda de peso, o descuido com a higiene do corpo, o fato de ficar sem dormir por longos períodos, devido ao efeito da droga e às queimaduras nos dedos e na boca, adquiridas pelo manejo da droga. Tais efeitos podem ser evidenciados na seguinte fala de uma das usuárias ${ }^{1}$ :

Eu cheguei a pesar cinquenta quilos, muito magra, muito feia, cabelo man tratado, a pele... não tinha mais vaidade nenhuma, às vezes eu passava dias sem tomar banho, sem escovar os dentes, sem fazer uma higiene pessoal, sem comer e sem beber água (Joana, 29 anos).

Como pode ser visto nessa fala, o consumo abusivo de pedras de crack está associado a comportamentos que podem fragilizar a saúde das usuárias, bem como favorecer a degradação do corpo e da aparência. Corroborando esses dados, o estudo conduzido por Etchepare, Dotto, Domingues e Colpo (2011) mostrou que $95,4 \%$ dos usuários de crack pesquisados $(n=24)$ tiveram os hábitos alimentares afetados pelo uso da droga. Esses usuários notaram diferença no apetite e não tinham horário certo para se alimentar, relatando não sentir fome quando usavam a droga.

Dessa forma, falar do usuário de crack é se referir a um sujeito submetido aos supostos "poderes devastadores" da substância. Em se tratando de mulheres, devem ser acrescentadas as representações de sujeira e de desmazelo corporal, pois são aspectos associados às noções de beleza, asseio corporal e cuidado com a saúde e com a estética, que constituem elementos

1 Foram utilizados nomes fictícios para preservar a identidade das participantes da pesquisa. 


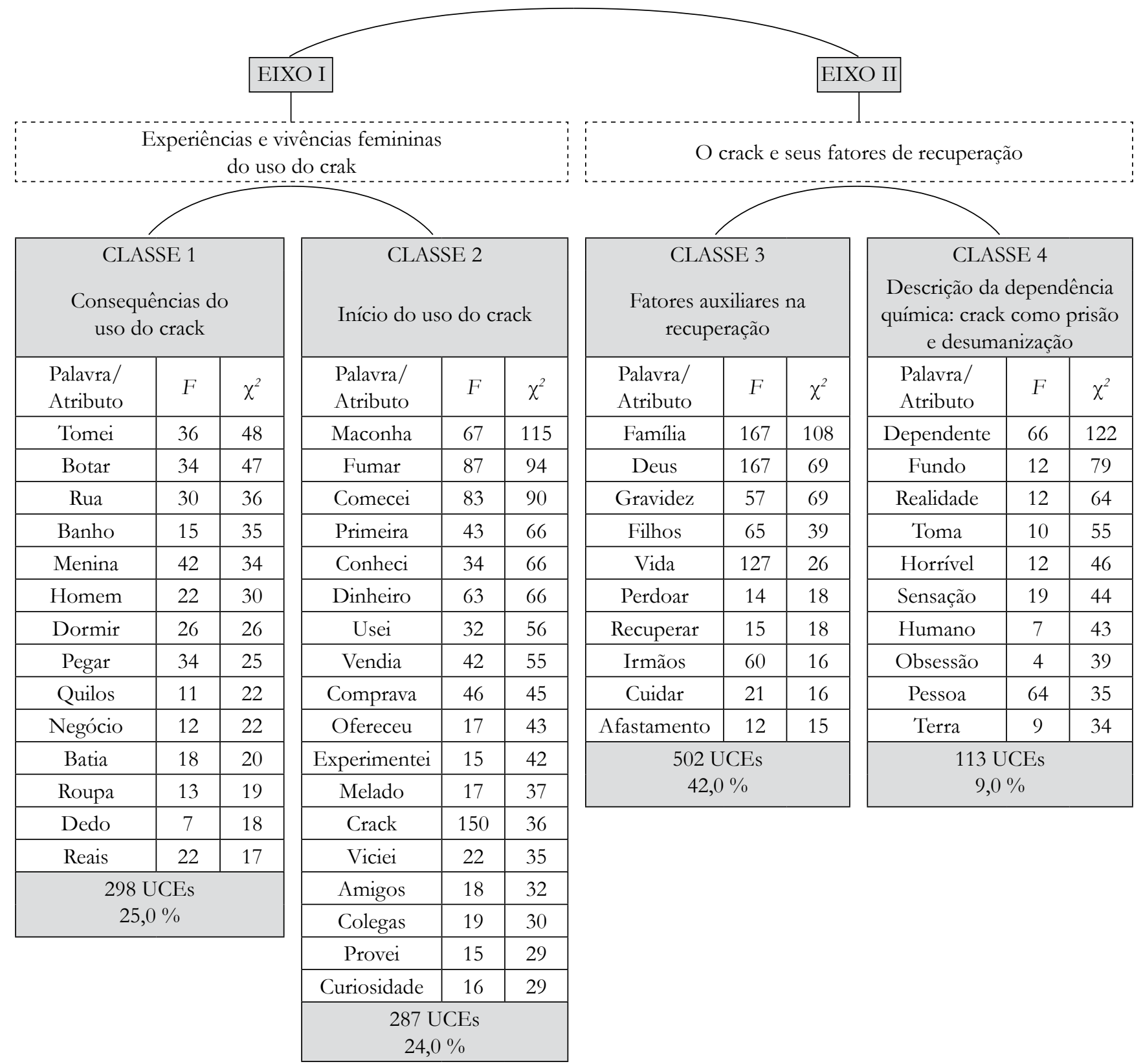

Figura 1. Dendrograma ou Classificação Hierárquica Descendente de Ascendente

cultivados e propagados como figurativos da mulher na sociedade atual.

Quanto às consequências sociais do consumo de crack, foram frequentes as palavras "rua" e "batia", relacionadas à exposição das usuárias, em grande parte do tempo, nas ruas, quando estavam sob o efeito da droga. Também foram relatadas situações de agressão e violência, cometidas contra as usuárias, como pode ser visto na seguinte fala: "Antes eu morava com meu tio, saí de casa e fui morar na rua, passei quatro meses na rua, debaixo do viaduto mesmo, com outros usuários, lá mesmo eu fumava e tinha para vender também né (...)" (Cristina, 25 anos).

De acordo com Silva (2000), desde o seu surgimento, o crack ficou conhecido como a "droga das ruas", devido ao seu baixo custo, que permite o acesso daqueles que não podem pagar por drogas consideradas mais sofisticadas. Uma vez que faz uso de uma substância ilícita, o usuário de droga carrega os estigmas de "drogado" e de "perigoso", somados ao fato de 
que "estar na rua" ou "morar na rua", favorece a sua representação como um sujeito "desviante", que oferece risco à sociedade.

Nas mulheres, esse cenário ganha ainda outros contornos, pois a constituição dos papéis sociais femininos sempre as alocou aos espaços privados, como o lar. De acordo com Pinho (2005), a saída desses espaços para ambientes públicos, notadamente a rua, provoca inúmeras significações, que permeiam o imaginário social, causando certo "estranhamento". Em sua pesquisa com usuárias de crack, Silva (2000) mostrou que, quando as mulheres ocupam contextos públicos, como um subterfúgio para o uso de drogas, tais espaços são considerados como territórios expostos, desprotegidos e favoráveis ao assédio. Esses aspectos concorrem para aumentar a vulnerabilidade dessas mulheres, tornando-as propensas a diversos agravos sociais e situações de agressão e violência, dentre as quais se destaca a violência sexual.

Nesse sentido, na presente pesquisa, a violência foi descrita como uma consequência social praticada contra as usuárias de drogas, ocorrendo especialmente em cenários de prostituição e também relacionada a dívidas com o tráfico. Isso pode ser constatado na fala a seguir:

Eu apanhei muito, porque eu dizia é tanto, ai ele não pagava e me batia, espancava e me mordia e tudo. E já levei muita coronhada na cabeça já, eles pegavam minha cabeça e jogava na parede do motel, uma vez ele queria pegar um copo de vidro de motel e jogar em cima de mim, e eu ficava com muito medo daquilo (Cristina, 20 anos).

É consenso, na literatura especializada, que usuários de crack estão mais expostos a situações de violência (Guimarães, Santos, Freitas, \& Araújo, 2008). Quando se trata de mulheres, nesse contexto de uso de crack, coexistem interações específicas, que envolvem níveis distintos e diferenciados de violência física e simbólica, tendo, na maioria dos casos, o homem como o agressor.

Esse dado reflete, sobretudo, a violência de gênero, uma vez que, historicamente, a dominação masculina sempre esteve presente nos diversos contextos e, em particular, nos ambientes de uso e venda de drogas. No entanto, como ressalva Ramos (2012), vem sendo cada vez mais comum encontrar mulheres chefiando postos antes vistos como exclusivamente masculinos, a exemplo do que acontece com as "bocas de fumo".

De modo geral, os discursos expressos nessa classe nos remetem aos danos causados pelo uso do crack, e por ser uma droga com alto poder de destruição, seja no âmbito individual ou social, a representação que esse grupo de pertença possui diante desse objeto social é permeada pela visualização dos malefícios do uso da droga, expressando o caráter negativo ou nocivo que este elemento representacional possui.

\section{Classe 2 - Início do Uso de Crack}

A classe 2, chamada de Início do uso de crack, foi formada por $287 \mathrm{UCE}$, contendo 132 palavras, significando $31,36 \%$ do corpus. Nessa classe, obtiveram maior expressividade as palavras "maconha", "amigos" e "curiosidade", denotando os motivos que levaram as mulheres ao uso de crack. De modo geral, esses motivos foram descritos, como: a utilização de outras drogas, como a maconha e o melado (cigarro composto pela mistura da maconha com o crack); a presença de amigos e/ou colegas, exercendo influência na iniciação do uso da droga; e a curiosidade em experimentar os efeitos da substância. As variáveis descritivas mais significativas compreenderam a faixa etária de 18 a 25 anos, a escolaridade média/superior e a renda acima de três salários mínimos.

Para vários autores, uma característica marcante do usuário de crack é o uso de inúmeras drogas antes de optar pelo crack (Bernardy \& Oliveira, 2010; Oliveira \& Nappo, 2008). Geralmente, o início se dá com o uso de drogas lícitas, como o álcool e o cigarro, que têm fácil circulação e aceitação social. Seguindo esse caminho, as usuárias adentram o mundo das drogas ilícitas, tendo a maconha ou o melado como a primeira droga consumida ilegalmente, como mostra o relato de uma das participantes:

Porque eu acho que a maconha é a porta para todas as outras drogas. Você a usa um tempo, mas depois você não quer mais ela, já quer outra (...) mas já não estava mais faz̧endo efeito porque eu estava usando com muita frequência então eu procurei uma coisa mais forte e encontrei o crack (Joana, 49 anos).

Pode-se verificar, no relato dessa usuária, a necessidade de substâncias capazes de proporcionar sensações mais intensas e prazerosas, o que explica a passagem do uso de drogas consideradas menos potentes, como a maconha, até chegar ao crack. Resultados semelhantes foram encontrados na pesquisa conduzida por Sanches e Nappo (2002), que aponta a sequência de drogas consumidas antes do crack, sendo a maconha descrita pelos usuários como a primeira droga ilícita consumida e que 
motivou a busca de outra substância que proporcionasse sensações mais fortes.

Outro fator levantado pelas usuárias, como motivo para a iniciação do uso de crack, foi a influência exercida por amigos ou companheiros. Para Gabatz et al. (2013), o consumo de droga pela primeira vez está associado a um ofertante, que disponibiliza o produto em troca de respeito e aceitação, para enfrentar a pressão social, bem como, pelo desejo de inserir-se em um grupo. O trabalho realizado por Nappo et al. (2004) revela que o início do uso do crack está relacionado a pessoas próximas às usuárias, como colegas e amigos $(45 \%)$, seguidos pelos companheiros $(27 \%)$. No caso específico das mulheres, chama a atenção o fato de que os companheiros exercem um papel determinante nas suas vidas. Segundo esses autores, quando os companheiros são os ofertantes, praticamente não existe recusa por parte delas, que, por nutrirem sentimentos de amor, companheirismo e até medo, acabam experimentando a droga. Isso pode ser exemplificado a partir do relato desta participante:

Eu comecei a usar porque meu marido chegou um dia com isso em casa, ele disse era bom, que vender daria dinheiro, a gente ia mudar de vida. Começamos a usar, só que eu fui pior ainda, usava mais e mais, já acordava pensando em usar (Jéssica, 27 anos).

Outro fator apontado como indutor para o início do uso do crack é a curiosidade em provar os efeitos da droga, como pode ser observado no relato a seguir: "Eu tava em um momento difícil da minha vida, eu caí, achando que as drogas tinha solução pra mim, tive curiosidade em provar, mas aí é que me enganei" (Marcela, 20 anos).

Alguns autores afirmam que, no início do uso de drogas, geralmente existe um movimento de busca por parte dos próprios usuários. A razão disso é que eles acreditam que o fato de experimentar não quer dizer necessariamente uma busca de aceitação, desafio ou respeito em relação a outrem. Significa simplesmente uma vontade própria ou curiosidade de sentir os efeitos da droga, o que remete a uma postura mais ativa do sujeito para procurá-la (Gabatz et al., 2013).

Apesar de a curiosidade estar presente em ambos os sexos, na fase de iniciação do uso de drogas, destaca-se o fato de que, nas mulheres, esse fator pode estar associado a um mecanismo de enfrentamento ou apoio emocional para suas angústias e preocupações (Diehl, Cordeiro, \& Laranjeira, 2011; Esper, Corradi-Webster, Carvalho, \& Furtado, 2013). A pesquisa efetuada por
Moos, Shutte, Brennan e Moos (2009) revela que o uso de substâncias por meninas está relacionado, sobretudo, a fatores de ordem psicológica, como ansiedade e depressão. Para lidarem com os problemas típicos da adolescência, as meninas recorrem às drogas, principalmente ao álcool.

De acordo com Pinho (2005), as exigências da pós-modernidade, impostas à figura da mulher, implicam uma carga social que nem sempre é suportada, causando "dilemas existenciais", ou, nos dizeres da autora, "um mal-estar inexplicável e ao mesmo tempo insuportável". Diante desse contexto, o que se observa é que, na maioria das vezes, a história de vida dessas mulheres e a relação com as drogas apontam justamente para uma forma possível de enfrentamento das dificuldades, com as drogas parecendo pôr termo ao seu sofrimento.

\section{Classe 3 - Fatores Auxiliares na Recuperacão}

A classe 3, categorizada como Fatores auxiliares na recuperação, com 502 UCE e 126 palavras, contabilizou $42,0 \%$ do corpus. Nessa classe, as falas remetem a fatores que auxiliam no processo de recuperação das dependentes químicas, aparecendo como expressivas as palavras "família", "filhos" e "Deus". Como variáveis descritivas de maior destaque, encontram-se as "mulheres em união estável" e as "desempregadas".

A família ocupou um lugar relevante nos discursos das usuárias, sendo considerada como uma importante fonte de apoio e suporte emocional necessário para a recuperação, como pode ser visto na fala a seguir:

Eu não vejo a hora de sair daqui pra reconstruir minha familia, por causa do crack me afastei deles, mas é por eles que eu vou voltar bem, recuperada (...) fico muito feliz quando eles vêm me visitar aqui, parece que renova minhas forças, a gente se sente bem, amada por eles (...) isso é tudo (Janaina, 26 anos).

No entender de Melmam (2001), por ser um cenário essencial na construção afetiva e social do sujeito, é atribuída à família toda a expectativa de apoio perante as dificuldades e sofrimentos enfrentados pelos seus membros no dia a dia. Nesse sentido, o suporte familiar mostra-se como um principal estímulo motivador no tratamento dos usuários, como mostram os estudos de Alvarez, Gomes, Oliveira e Xavier (2012) e Peixoto et al. (2010).

Corroborando esse ponto de vista, o trabalho de Carbonera, Silva, Nascimento-André e Legal (2013) demonstrou que a motivação por parte de um familiar 
constitui um fator importante para o tratamento de usuários de drogas, tanto para homens como para mulheres. Porém, enquanto os familiares encorajam os homens a parar de usar drogas, as mulheres relatam que se sentem pouco apoiadas, seja porque a família nega, seja porque se sente envergonhada por seu comportamento. Os resultados encontrados por Nóbrega e Oliveira (2005) mostram que elas raramente comparecem, ao tratamento, acompanhadas por algum familiar ou pelo companheiro. Além disso, geralmente solicitam que a busca de tratamento não seja revelada à família, devido à vergonha e ao receio de fracassarem.

Outro fator apresentado pelas participantes desta pesquisa, como elemento motivacional auxiliar na recuperação, foi constituído pelos filhos, conforme pode ser visto no relato que se segue:

Eu tô muito feliz que eu tô grávida. Ai a vontade de sair do crack vem desse menino que tô esperando, sabe? Porque eu procurei força e não consegui, en voltei de novo. Eu preciso sair disso tudo para poder cuidar dele (Janaina, 26 anos).

É consenso na literatura científica da área que, quando são usuárias de drogas e negligenciam tais comportamentos de proteção e cuidado materno, as mulheres passam a ser taxadas, pela sociedade, como egoístas e irresponsáveis para com os filhos. Isso faz com que muitas delas se sintam incapazes de cumprir o papel que lhes foi designado, optando por distanciar-se dos filhos, como forma de protegê-los (Pinho, 2005).

Resultado semelhante foi relatado por Oliveira e Paiva (2007), em seu estudo com usuárias de crack. A maternidade foi referida, pelas entrevistadas, como uma consequência não planejada dos relacionamentos sexuais mantidos sem uso de preservativo e/ou de qualquer outro método contraceptivo. $\mathrm{Na}$ tentativa de atender aos padrões socialmente construídos para a mulher, as usuárias de drogas deste estudo revelaram abrir mão do convívio direto com os filhos, como atitude de proteção. Para os autores, o fato de afastar-se dos filhos, mantendo-os longe de um ambiente onde o consumo e o tráfico de drogas são altos, parece, de alguma forma, colocá-las mais próximas dos papéis sociais culturalmente estabelecidos para as mulheres, de mães cuidadoras e protetoras.

No entanto, este estudo mostra que, apesar do distanciamento que o crack provoca na relação mãe-filhos, a recuperação é vista como o retorno ao lar, e notadamente ao convívio com os filhos. A presença destes é vista como suporte para buscar uma nova vida longe das drogas, servindo como estímulo motivacional a procura de tratamento, bem como, engajar-se no processo de recuperação.

\section{Classe 4 - Descrição da Dependência do Crack: Prisão e De- sumanização}

A classe 4, Descrição da dependência química do crack: prisão e desumanização, conteve 113 UCE e 124 palavras, expressando 9,0\% do corpus. As falas dessa classe dizem respeito às descrições da dependência do crack, expressas por meio das consequências da dependência química em suas vidas. As palavras que se mostraram mais proeminentes a esse respeito foram "dependente", "fundo do poço" e "humano". As variáveis descritivas que ganharam mais destaque foram referentes às mulheres que tinham estudos "médios/ superiores" e eram "divorciadas/viúvas".

Com os termos "dependente" e "fundo do poço", as usuárias expressam a sua compulsão pela substância, referindo-se à dependência química como uma prisão, na qual chegaram a uma condição extrema. Por meio desses discursos, deixam evidente o desejo de libertar-se desse aprisionamento:

Ela é uma droga que lhe prende pra tudo (...) e ser depen-
dente de uma droga é uma pessoa ser prisioneira a ela. E
agora eu não sou mais prisioneira a ela, agora eu sou uma
mulher libertada, antes eu não era assim. Antes eu era uma
mulher prisioneira à droga, e hoje eu já não sou, eu não me
acho prisioneira (Francisca, 43 anos).

Como pôde ser observado nesse discurso, há uma representação da dependência química associada à perda de controle do uso da droga, provocando sintomas psíquicos de impotência. Em si tratando do crack, essa impotência se torna mais evidente, uma vez que esse tipo de droga causa fortes sintomas de abstinência, quando há descontinuidade no seu uso (Kessler \& Pechansky, 2008).

Por seu lado, a palavra "humano" expressa o desejo de tratamento, uma vez que remete à condição sub-humana que a dependência química ocasiona na vida do usuário. Essa reflexão se manifesta neste discurso de uma das participantes:

Nenhum ser humano merece viver assim, todo dia drogado (...) a gente precisa viver, se sentir triste, chorar, rir como uma pessoa normal (...) o crack faz a gente virar um bicho (...) isso não quero mais, vou sair dessa vida (Júlia, 45 anos).

Psico-USF, Bragança Paulista, v. 20, n. 3, p. 517-528, set./dez. 2015 
Nessa fala, observa-se que a vivência com o crack foi colocada, pelas usuárias, como sinônimo de desumanização. Por outro lado, o tratamento foi encarado como um processo de resgate da condição humana e das possibilidades da vida cotidiana e do futuro sem o crack. Os dados encontrados na presente pesquisa corroboram os achados de Carbonera et al. (2013), que revelaram que as marcas deixadas pela dependência são representadas, pelos usuários, como impedimentos e até rupturas em suas rotinas. Nesses casos, o tratamento tem a função de contribuir para que o ser humano possa desenvolver-se com autonomia e senso crítico, para poder decidir, por conta própria, como agir nas diversas situações da vida.

Os resultados aqui apresentados revelam representações imbuídas de conteúdos de ordem individual, familiar e social. Diante dessas questões, denota-se a necessidade de se olhar todas as nuances desse fenômeno, na tentativa de favorecer o cuidado e a assistência que esse público feminino tanto necessita e que fala de vivências que vão além da questão orgânica, que ultrapassam as fronteiras dos livros e abarcam o dia a dia delas; falando de prisão de um modo subjetivado e ancorado na dependência que aprisiona a mente, o corpo e seus sonhos; tirando o que elas têm de mais humano, o ser sujeito de direito, ser mãe e ser mulher.

\section{Considerações Finais}

$\mathrm{Na}$ presente pesquisa, as representações sociais do uso do crack, elaboradas por mulheres em tratamento, geraram conhecimentos que podem contribuir para ampliar o entendimento sobre a relação que o universo feminino estabelece com essa droga. Nessa relação, devem ser considerados não somente os fatores que levam ao uso, mas também as repercussões que estão implicadas na vivência da dependência química na sociedade, abarcando além das vivências pessoais e familiares as questões de ordem social.

De modo geral, as mulheres usuárias de drogas não configuram um grupo homogêneo; contudo, de acordo com os levantamentos aqui assinalados, apontam para um perfil com menor nível socioeconômico, baixa escolaridade, fora do mercado de trabalho formal, em idade fértil e com filhos, com menos acesso aos serviços de cuidado e de proteção, o que as expõe a diversos fatores de vulnerabilidade e de risco social.

Se todos os usuários abusivos de drogas já são colocados à margem da sociedade, no caso das mulheres, o isolamento é mais amplo, pois é permanentemente reforçada por um registro social que estigmatiza a dependência química feminina. Historicamente, as mulheres sempre foram mais criticadas do que os homens por usarem álcool ou outras drogas, sendo acusadas por não cumprirem as funções femininas ou de se tornarem sexualmente promíscuas quando intoxicadas. A consequência dessas representações é um movimento de rejeição e exclusão social mais marcante em relação à mulher. Esse fator tem impacto na procura e/ou na permanência desta nos serviços de tratamentos.

Os resultados indicaram que o crack é representado como um elemento devastador e desagregador, por gerar problemas orgânicos e situações de desordem no ambiente familiar e por ser responsável por causar abandono ou afastamento do lar e dos filhos. Além disso, as representações acerca da forma como a sociedade encara a mulher dependente química recheada de questões moralizantes, reforça barreiras sociais que dificultam a procura de tratamento e a recuperação das usuárias. Fato esse preocupante, visto que são assinaladas pelas entrevistadas a degradação física, como perda de peso e queimaduras nos dedos e na boca; além das situações de violência ocorridas em cenários de prostituição e dívidas com o tráfico. Dessa forma, pode-se afirmar que é necessário um olhar para além da estigmatização da mulher, a qual deve ser vista, antes do papel de esposa ou mãe, como mulher que necessita ter seus direitos preservados e acesso a um tratamento adequado dentro das novas políticas de saúde.

As limitações da presente pesquisa residem na cautela que se deve ter quanto à generalização de tais achados para a população em geral. No entanto, os dados encontrados sinalizam para que outras investigações possam se debruçar sobre essa temática, buscando analisar lacunas que extrapolam os objetivos ora propostos.

Contudo, as reflexões aqui apresentadas têm sua importância e remontam a necessidade de implantação de estratégias para o enfrentamento do fenômeno do crack, baseadas em especificidades individuais e grupais, de forma a contemplar a heterogeneidade dos sujeitos em seus distintos contextos. Compreendidas como um conhecimento socialmente construído e partilhado, as representações sociais das entrevistadas mostraram-se atreladas à realidade das mulheres, refletindo construções socioculturais. Dessa forma, os resultados do presente estudo podem impulsionar reflexões acerca da temática do uso de drogas entre as mulheres, possibilitando o despertar de ressignificações de imagens e representações. Notadamente, apontam para a urgência 
de ampliação da rede de serviços concernentes à saúde mental, na assistência à mulher dependente química; e para a criação de políticas públicas que contemplem as especificidades femininas, visando um trabalho de prevenção e de intervenção mais eficaz na questão do crack na sociedade.

\section{Referências}

Alvarez, S. Q., Gomes, G. C., Oliveira, A. M. N., \& Xavier, D. M. (2012). Grupo de apoio/suporte como estratégia de cuidado: importância para familiares de usuários de drogas. Rev. Gaúcha Enferm., 33(2), 102-108. Recuperado de http://www.scielo.br/ $\mathrm{pdf} /$ rgenf/v33n2/15

Bernardy, C. C. F., \& Oliveira, M. L. F. (2010). O papel das relações familiares na iniciação ao uso de drogas de abuso por jovens institucionalizados. Rev. Esc. Enferm. USP, 44(1), 11-7. doi: 10.1590/ S0080-62342010000100002.

Brasil (2013). Ministério da Saúde. Fundação Oswaldo Cruz. Perfil dos usuários de crack e/ ou similares no Brasil. Recuperado de http://portal.fiocruz.br/pt-br/ content/maior-pesquisa-sobre-crack-j\%C3\%A1-feita-no-mundo-mostra-o-perfil-do-consumo-no-brasil.

Bungay, V., Johnson, J. L., Varcoe, C., \& Boyd, S. (2010). Women's health and use of crack cocaine in context: Structural and everyday "violence". International Journal of Drug Policy, 21, 321-329. doi: 10.1016/j.drugpo.2009.12.008

Camargo, B. V. (2005). Alceste: Um programa informático de análise quantitativa de dados textuais. In A. S. P. Moreira et al. (Eds.). Perspectivas teórico-metodológicas em representações sociais (pp. 511-539). João Pessoa: Editora Universitária-UFPB.

Campos, A., Trindade, L., \& Coelho, L. (2008). Mulheres criminosas na abordagem interdisciplinar. Pesquisa em Debate, 5(2), 1-15. Recuperado de http://www.pesquisaemdebate.net/docs/pesquisaEmDebate_9/artigo_1.pdf

Carbonera, A., Silva, D. G., Nascimento-André, M. I., \& Legal, E. J. (2013). Dando voz a mulheres em tratamento da dependência de substâncias psicoativas. Revista de Psicologia da IMED, 5(2), 109-114. Recuperado de http://www.dialnet.unirioja.es/ descarga/articulo/5155025.pdf
Carlini, E. A., Galduróz., J. C. F., Noto, A., R., \& Nappo, S., A. (2002) - I levantamento domiciliar sobre o uso de drogas no Brasil - estudo envolvendo as 107 maiores cidades do país - 2001. Centro Brasileiro de Informações sobre Drogas Psicotrópicas (pp. 480). Departamento de Psicobiologia da Escola Paulista de Medicina e Senad - Secretaria Nacional Antidrogas, Presidência da República, Gabinete de Segurança Nacional.

Colling, A. (2004). A construção histórica do feminino e do masculino. In M. N. Strey, S. T. L. Cabeda \& D. R. Prehn (Eds.), Gênero e cultura: Questões contemporâneas (pp. 13-38). Porto Alegre: EDIPURCRS.

Coutinho, M. P. L., Araújo, L. F., \& Gontiés, B. (2004). Uso da Maconha e suas representações sociais: Estudo comparativo entre universitários. Psicologia em Estudo, 9(3), 469-477. doi: 10.1590/ S1413-73722004000300015.

Diehl, A., Cordeiro, D., C., \& Laranjeira, R. (2011). Dependência química: Prevenção, tratamento e políticas públicas. Porto Alegre: Artmed.

Esper, L. H., Corradi-Webster, C. M,. Carvalho, A. M. P., \& Furtado, E. F. (2013). Mulheres em tratamento ambulatorial por abuso de álcool: Características sociodemográficas e clínicas. Rev. Gaúcha Enferm., 34(2), 93-101. doi: 10.1590/ S1983-14472013000200012.

Etchepare, M., Dotto, E. R., Domingues K. A., \& Colpo, E. (2011). Perfil de adolescentes usuários de crack e suas consequências metabólicas. Revista da AMRIGS, Porto Alegre, 55(2): 140-146. Recuperado de http://www.amrigs.com.br/ revista/55-02/013-PG_140-146_757_perfil\%20 de $\% 20$ adolescentes.pdf

Gabatz, R. I. B., Schmidt, A. L., Terra, M. G., Padoin, S. M. M., Lacchini, A. G. B., \& Silva, A. A. (2013). Percepção dos usuários de crack em relação ao uso e tratamento. Rev. Gaúcha Enferm., 34(1), 140-146. doi: 10.1590/S1983-14472013000100018.

Guimarães, C. F., Santos, D. V. V., Freitas, R. C., \& Araújo, R. B. (2008). Perfil do usuário de crack e fatores relacionados à criminalidade em unidade de internação para desintoxicação no Hospital Psiquiátrico São Pedro de Porto Alegre (RS). Rev. Psiquiatr. RS, 30(2), 101-108. doi: 10.1590/ S0101-81082008000300005. 
Hochgraf, P. B., \& Andrade, A. G. (2006). A questão do gênero nas farmacodependências. In T. A. Cordás \& F. T. Salzano (Eds.), Saúde Mental da Mulher (pp. 85-103). São Paulo: Atheneu.

Jodelet, D. (2001). Representações sociais: Um domínio em expansão. In D. Jodelet (Org.), As representações sociais. Rio de Janeiro: EdUerj.

Kessler, F., \& Pechansky, F. (2008). Uma visão psiquiátrica sobre o fenômeno do crack na atualidade. Revista de Psiquiatria do Rio Grande do Sul, 30(2), 96-98. Recuperado de http://www.scielo.br/pdf/ rprs/v30n2/v30n2a03

Marangoni, S. R. (2010). Contextos de exclusão social e vulnerabilidade de mulheres usuárias de drogas no ciclo gravídico puerperal (Dissertação de mestrado). Universidade Estadual de Maringá, Maringá, PR.

Marangoni, S. R., \& Oliveira, M. L. F. (2012). Uso de crack por multípara em vulnerabilidade social: História de vida. Ciênc. Cuid. Saúde, 11(1), 166-172. doi: 10.4025 .

Melman, J. (2001). Familia e doença mental: Repensando e relação entre profissionais de saúde e familiares. São Paulo: Escrituras Editora.

Medeiros, K. T. (2014). As mulheres no fenômeno das drogas: Representações sociais de usuárias de crack (Dissertação de mestrado). Universidade Federal da Paraíba, João Pessoa, PB.

Minayo, M. C. S. (2012). O desafio do conbecimento: Pesquisa qualitativa em saúde. (12a ed.). São Paulo: Hucitec.

Moos, R. H., Shutte, K. K., Brennan, P. L., \& Moos, B. S. (2009). Older adult's alcohol consumption and late-life drinking problems: a 20-year perspective. Addiction, 104(8), 1293-302. doi: 10.1111/j.1360-0443.2009.02604.x.

Nappo, S. A., Sanchez, Z. V. M., Oliveira, L. G., Santos, S. A., Coradete Jr., J., Pacca, J. C. B., \& Lacks, V. (2004). Comportamento de risco de mulheres usuárias de crack em relação às DST/Aids. São Paulo: CEBRID - Centro Brasileiro de Informações sobre Drogas Psicotrópicas.

Nobrega, M. P. S. S., \& Oliveira, E. M. (2005). Mulheres usuárias de álcool: Análise qualitativa. Rev. Saúde Pública, 39(5), 816-823. Recuperado de http:// www.scielo.br/pdf/rsp/v39n5/26304.pdf

Oliveira, L. G., \& Nappo, S. A. (2008). Caracterização da cultura de crack na cidade de São Paulo: Padrão de uso controlado. Rev. Saúde Pública, 42(4), 664-71. doi: 10.1590/S0034-89102008005000039.

Oliveira. J. F., Nascimento, E. R., \& Paiva, M. S. (2007). Especificidades de usuários(as) de drogas visando uma assistência baseada na heterogeneidade. Esc Anna Nery Rev. Enferm., 11(4), 694 -8. doi: 10.1590/ S1414-81452007000400022.

Oliveira, J. F., \& Paiva, M. S. (2007). Vulnerabilidade de mulheres usuárias de drogas ao hiv/ aids em uma perspectiva de gênero. Esc Anna Nery Rev Enferm. 11(4), 625-31. doi: 10.1590/ S1414-81452007000400011.

Peixoto, C., Prado, C. H. O., Rodrigues, C. P., Cheda, J. N. D., Mota, L. B. T., \& Veras, A. B. (2010). Impacto do perfil clínico e sociodemográfico na adesão ao tratamento de pacientes de um Centro de Atenção Psicossocial a Usuários de Álcool e Drogas (CAPSad). J. Bras. Psiquiatr. 59(4), 317-321. doi: 10.1590/S0047-20852010000400008.

Pinho, G. S. A. (2005). "Minha saúde não é de ferro, mas meus nervos são de aço": A mulher e o uso de drogas na sociedade contemporânea. Mnemosine, 1(1), 278-345. Recuperado de http://www. mnemosine.com.br/ojs/index.php/mnemosine/ article/view/54

Ramos, L. S. (2012). Por amor ou pela dor? Um olhar feminista sobre o encarceramento de mulheres por tráfico de drogas (Dissertação de mestrado). Universidade de Brasília, DF.

Reinert, M. (1993). Quelques aspects du choix des unités d'analyse et de leur contrôle dans la méthode "Alceste". Recuperado de http://www.image-zafar.com/publication/JADT1995Rome.pdf. Acesso em: 30, ago, 2013.

Relatório Mundial Sobre Drogas - (UNODC). (2012). Recuperado de http://www.unodc.org/southerncone/pt/drogas/relatorio-mundial-sobre-drogas. html

Sanchez, Z. M., \& Nappo, S. A. (2002). Sequência de drogas consumidas por usuários de crack e fatores interferentes. Rev Saúde Pública, 36(4), 420-30. doi: 10.1590/S0034-89102002000400007.

Santos, G. L., \& Almeida, D. C. (2013). Estudo do perfil das dependentes químicas usuárias do centro de atendimento psicossocial álcool e drogas - CapsAd do município de Caçador/SC. Revista 
Interdisciplinar de Estudos em Saúde, 2(1), 42-57. Recuperado de http://www.periodicosuniarp.com.br/ ries/article/view/106

Silva, S. L. (2000). Mulheres na luz: Uma etnografia dos usos e preservação no uso do crack. (Dissertação de mestrado). Universidade de São Paulo, SP.
Yamaguchi, E. T., Cardoso, M. M. S. C., Torres, M. L. A., \& Andrade, A. G. (2008). Drogas de abuso e gravidez. Rev. Psiq. Clín., 35(1), 44-47. doi: 10.1590/ S0101-60832008000700010.

Recebido: 08/07/2014 Primeira reformulação: 11/02/2015 Segunda reformulação: 02/03/2015

Aprovado: 13/03/2015

Nota das autoras:

Pesquisa financiada pela Capes.

Sobre as autoras:

Katruccy Tenório Medeiros é psicóloga, mestre e doutoranda em Psicologia Social pela UFPB, e membro do Grupo de Pesquisa em Saúde Mental e Dependência Química - GPSMDQ/UFPB.

E-mail: katruccy_22@yahoo.com.br

Silvana Carneiro Maciel é professora, doutora do Departamento de Psicologia na UFPB e da Pós-graduação em Psicologia Social-UFPB, e coordenadora do Grupo de Pesquisa em Saúde Mental e Dependência Química - GPSMDQ/UFPB.

E-mail: silcamaciel@gmail.com

Patrícia Fonseca de Sousa é psicóloga e mestre em Psicologia Social pela UFPB.

E-mail: patriciasousa20@yahoo.com.br

Giselli Lucy Souza Vieira é psicóloga, especialista em Saúde Mental pela FIP e mestre em Psicologia Social pela UFPB.

E-mail: giselli_psi@hotmail.com

Contato com as autoras:

Katruccy Tenório Medeiros

E-mail: katruccy_22@yahoo.com.br

Rua Lindolfo G. Chaves, 145, Ed. Jardim Paulista, Apt. 205

Bancários, João Pessoa/PB

CEP: 58051-200. 